\title{
Gold Nanorods Embedded in Polymeric Film for Killing Bacteria by Generating Reactive Oxygen Species with Light
}

\author{
Francesco Rossi, ${ }^{\dagger, \neq, \S}$ Nguyễn T. K. Thanh, ${ }^{* \dagger, \dagger \oplus}$ and Xiao Di Su ${ }^{*, \S, \perp, \pi}$
}

\begin{abstract}
${ }^{\dagger}$ Biophysics Group, Department of Physics \& Astronomy, University College London, Gower Street, London WC1E 6BT, U.K.
${ }^{\ddagger}$ UCL Healthcare Biomagnetic and Nanomaterials Laboratories, Royal Institution of Great Britain, 21 Albermarle Street, London W1S 4BS, U.K.

${ }^{\S}$ Institute of Materials Research and Engineering, A*STAR (Agency for Science, Technology and Research), 2 Fusionopolis Way, Innovis, \#8-03, Singapore 138634, Singapore

${ }^{\perp}$ Department of Chemistry, National University of Singapore, Block S8, Level 3, 3 Science Drive 3, Singapore 117543, Singapore

${ }^{I}$ School of Engineering and Science, University of the Sunshine Coast, 90 Sippy Downs Drive, Sippy Downs Queensland 4556, Australia
\end{abstract}

\section{Supporting Information}

ABSTRACT: For the first time, anisotropic gold nanorods (AuNRs) were embedded with a photosensitizer dye (crystal violet) in polyurethane (PU) matrix to create the effective antimicrobial film, capable of killing Gram-negative bacteria on its surface when exposed to white light. The dye, when activated with white light, interacts with the AuNRs to generate reactive oxygen species (ROS), which kill bacteria. With a proper control of the aspect ratio $(2.1-2.4)$ and coating of the AuNRs, the film can be tuned to reduce the bacteria population of one to four orders of magnitude (1-log to 4$\log$ ) under 11 klux of light, for an exposure to light between 1 to $3 \mathrm{~h}$. Particularly it could reduce $10^{4} \mathrm{cfu} / \mathrm{cm}^{2}$ to the level of $1-5 \mathrm{cfu} / \mathrm{cm}^{2}$ in $3 \mathrm{~h}$ of light exposure. This was a desired performance for use on hospital surfaces. In addition, the system showed antimicrobial effect only when exposed to light, which eliminated the concern for a cumulative toxic effect on subjects exposed to the material for a long period of time and limited the time given to the bacteria to develop resistance against the system.

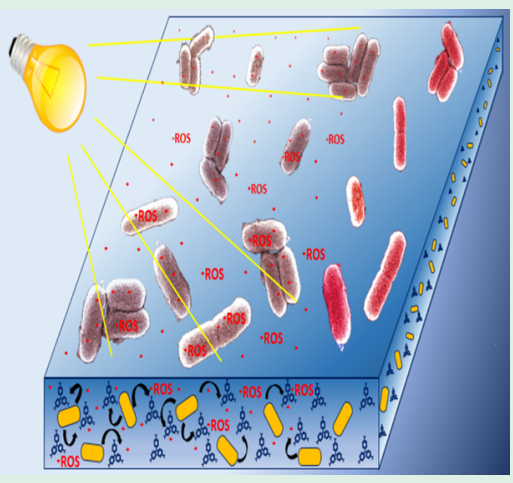
Furthermore, this process of sterilization could be carried out by a commercially available white light lamp, which when in use did not interrupt the normal routine operation of the environment.

KEYWORDS: antibacterial film, sterilization, light activated, nanorods, nanomaterials, noncontact disinfection

\section{INTRODUCTION}

With the emerging of antibiotic resistant bacteria, the development and maintenance of sterile environments is becoming a necessity for hospitals and food manufactures. The weight of infections caused by multidrug resistant bacteria, on the US health system, is of 55 billion USD per year, ${ }^{1}$ and projections estimate an impact on the world economy for trillions USD yearly by the $2050 .^{2}$ Infections from drug resistant bacteria are often contracted in environments where bacteria are exposed to drugs with frequent and incomplete cycles of disinfections, in hospitals or food processing facilities. The development of hospital acquired infections (HAI) involves $5 \%$ of the intensive care patients in developed countries (47.9 cases for 1000 hospital hours) and $15.5 \%$ of the patients of the developing countries, ${ }^{3}$ while crosscontamination during the handling of food causes a great number of diseases every year (9.4 million of illnesses and 2612 casualties in the 2011). ${ }^{4}$ Conventional sterilization methods are not effective; they require intensive resources (e.g., chemicals and sterilizing apparatus) and effort from skilled operators working in the sterile environment. ${ }^{5,6} \mathrm{~A}$ typical hospital surface has $2-5$ colonies forming units (cfu) per $\mathrm{cm}^{2}$ (with peaks of $40-300 \mathrm{cfu} / \mathrm{cm}^{2}$ on ward surfaces or hospital kitchens) against a tolerant level of $<1 \mathrm{cfu} / \mathrm{cm}^{2}{ }^{7,8} \mathrm{~A}$ food preparation plant can have as much as 1000-100000 $\mathrm{cfu} / \mathrm{cm}^{2}$ especially on the preparation tables and abattoir surfaces, ${ }^{9}$ which is far from the tolerant level of 500-5000 cfu/ $\mathrm{cm}^{2}$ for meat preparations before cooking and 50 to $500 \mathrm{cfu} /$ $\mathrm{cm}^{2}$ for minced meat. ${ }^{10}$ Sterilization based on wiping with detergents or chemicals is labor intensive and depends completely on skilled personnel working in the sterile environment. Tests performed in hospitals around the world have shown that chemical based routine cleaning is not thorough enough to achieve the required sterility standards in more than $40 \%$ of the surfaces in close contact with patients. $^{11-13}$ To improve the efficiency of cleaning processes, noncontact sterilization methods utilizing reactive gas or UV light have been introduced. However, these methods have a

Received: April 26, 2019

Accepted: May 13, 2019

Published: May 14, 2019 
destructive effect on the surfaces and instruments, and their use is limited to terminal or deep cleaning. ${ }^{14-16}$ An alternative approach to reduce contamination without direct intervention could be the introduction of antimicrobial surfaces. Antimicrobial surfaces can be based on either materials that slowly release antimicrobial active substances (proteins, antibiotics, or heavy metal ions as copper and silver) or in being able to catalyze the formation of reactive oxygen species (ROS) when interacting with a source of energy (UV, laser, or white light). ${ }^{16}$ Surfaces based on the release of antimicrobial substances have a good activity in a short period. However, there are concerns about long-term efficiency because the slow release of antimicrobial substances can trigger the development of bacterial resistance. ${ }^{16}$ For light activated antimicrobial films, especially those involving nanomaterials, one of the advantages is the use of lower intensity light radiation to activate the antimicrobial effect compared to the use of light alone. One example of this kind of surfaces is composed of a silicon matrix containing $\mathrm{TiO}_{2}$ nanoparticles. ${ }^{17}$ The presence of nanoparticles reduces the time of exposure required to kill bacteria but still requires UV light to be activated, which limits the access to the sterilized area. More recently, hybrid systems based on metal nanoparticles, particularly small spherical gold nanoparticles ( $<5 \mathrm{~nm}, \mathrm{AuNPs})$, and a sensitizer dye have been introduced. This nanoparticle based catalysis of ROS shows a great antimicrobial activity under the exposure to laser light in the visible range. ${ }^{18,19}$ In a normal white light condition, it requires as long as $6 \mathrm{~h}$ to reach to comparable level of activity as that using laser light. Moreover, this system has certain toxicity in the dark that may limit its application. ${ }^{20}$ In the past decade, anisotropic metal nanoparticles, as gold nanorods (AuNRs), have attracted interest for medical applications due to their strong localized electromagnetic field and intense plasmonic properties; ${ }^{21}$ however, they were never been used for antimicrobial surfaces. The antibacterial film proposed in this work uses AuNRs as an energy collector to increase the quantity of ROS generated by a photosensitizer dye, throughout plasmonic coupling. The introduction of rodshaped gold nanoparticles of suitable aspect ratio (2.1-2.4) and UV-visible absorption range, according to the photosensitizer dye's absorption spectrum, increases/steps up the activity of the system when exposed to white neon light. The energy absorbed by the film led to the production of ROS, ${ }^{22}$ which are able to damage the bacteria attached to the film surface. In contrast to the traditional methods of sterilization that rely on the application of chemical substances (70\% ethanol, hydrogen peroxide, peracetic acid, chlorine releasing agents, acid and basic solutions) $)^{23,24}$ or the use of sterilizing apparatus (autoclaves, UV chamber, ionizing radiations, high temperature dry sterilization), ${ }^{25}$ this system maintains a continuous antimicrobial effect, and it is powered by merely exposure to a commercially available white light lamp without any direct intervention. This attribute makes this film an innovative way of reducing the risk of developing resistant bacterial strains due to an incomplete cleaning process, ${ }^{26}$ while being nontoxic when not exposed to light, thus limiting the time given to the bacteria to develop resistance. ${ }^{27}$

\section{MATERIALS AND METHODS}

2.1. Reagents. Hexadecyltrimethylamonium bromide (CTAB, $\geq$ 98\%) was purchased from Tokyo Chemical Industry. Hydrogen tetrachloroaurate solution $\left(\mathrm{HAuCl}_{4}, 30 \mathrm{wt} \%\right)$, sodium borohydride $\left(\mathrm{NaBH}_{4}, \geq 98 \%\right)$, silver nitrate $\left(\mathrm{AgNO}_{3}, \geq 99.0 \%\right)$, sodium bromide
$(\mathrm{NaBr}, \geq 99,99 \%)$, L-ascorbic acid $\left(\mathrm{C}_{6} \mathrm{H}_{8} \mathrm{O}_{6}, \geq 99 \%\right)$, poly(sodium 4styrenesulfonate) (NaPSS, $\mathrm{Mw} 70 \mathrm{kDa}$ ), sodium citrate (citNa, > 99\%), thiol-polyethylene glycol-carboxylic acid (thiol-PEG, > 99\%), sodium chloride $(\geq 99 \%)$, sodium fluorescein (fluorescent tracer grade), and sodium hydroxide $(\mathrm{NaOH}, \geq 97 \%)$ were obtained from Sigma-Aldrich, Singapore. $\mathrm{H}_{2} \mathrm{O}_{2}$ solution (30-32 wt \%) was acquired from QüreC (Quality Reagents Chemical, New Zealand), while hydrochloric acid ( $\mathrm{HCl}, 36-38$ wt \%, Duskan Pure Chemical) was acquired from Duskan Reagents, Singapore. Polyurethane $(1 \mathrm{~mm}$ thick, Swees Engineering Co., pte, PU) and crystal violet ( $\geq 99 \%$, Certistain, CV) were obtained from MERK, Singapore; Nutrient Agar (NA) CM0003 was obtained from Oxoid).

2.2. Gold Nanorods Preparation. Gold nanorods (AuNRs) were prepared using a modified seed mediated synthesis approach. ${ }^{28-30}$ Surfactant micelles (CTAB) were used as template to grow nanorods from seeds formed in a different solution. ${ }^{31}$ The surfactant was then removed, and the resulting AuNRs were stabilized by either citNa or thiol-PEG. Details procedures are described below. The seeds solution was prepared by mixing $5 \mathrm{~mL}$ of an aqueous solution of $0.5 \mathrm{mM} \mathrm{HAuCl}_{4}$ with $5 \mathrm{~mL}$ of $0.2 \mathrm{M} \mathrm{CTAB}$ and reduced with $0.6 \mathrm{~mL}$ of an ice cold $10 \mathrm{mM} \mathrm{NaBH}_{4}$ solution. After the reaction, the solution was left to incubate for $1 \mathrm{~h}$ to allow the Ostwald ripening to focus the size and shape of the seeds formed. ${ }^{32}$ The growth solution was prepared by adding $75 \mu \mathrm{L}$ of $10 \mathrm{mM} \mathrm{AgNO}_{3}$ to a $5 \mathrm{~mL}$ of a solution $0.2 \mathrm{M}$ of $\mathrm{CTAB}$ and later adding $5 \mathrm{~mL}$ of $1.4 \mathrm{mM}$ $\mathrm{HAuCl}_{4}$, followed by $0.25 \mathrm{~mL}$ of $1.25 \mathrm{M} \mathrm{NaBr}$. When all the components were added to the batch, it was left incubating for at least $15 \mathrm{~min}$ and then reduced with $105 \mu \mathrm{L}$ of $79 \mathrm{mM} \mathrm{L}$-ascorbic acid. After $30 \mathrm{~s}$ of agitation, $60 \mu \mathrm{L}$ of seeds solution was added to trigger the formation of the rods. The solution was left incubating for $12 \mathrm{~h}$ at 30 ${ }^{\circ} \mathrm{C}$ to complete the growth process. After the synthesis, the particles were stabilized by a bilayer of cationic surfactant (CTAB), which was the main component of the growth solution. This surfactant is strongly toxic against bacteria and human tissues (liver and heart), while gold nanorods stabilized with nontoxic capping agents (e.g., PEG or sodium citrate) are widely considered biocompatible. ${ }^{33}$ The surfactant was removed from the surface of the particles with cycles of centrifugation $(14000 \mathrm{rpm}, 10 \mathrm{~min}$ using Mikro 220R Hettich centrifuge). ${ }^{34}$ The resulting concentrated suspension of gold nanorods was redispersed in microfiltered deionized water, followed by two cycles of centrifugation (14000 rpm, $7 \mathrm{~min}$ ) and finally redispersed in a solution of poly(sodium 4-styrenesulfonate) (PSSNa) $0.15 \% \mathrm{w} / \mathrm{w}$, which acted as a temporary capping agent to remove the CTAB strongly attached to the surface of the rods. ${ }^{34}$ After the last cycle of CTAB removal with PSSNa, the surface of the particles was modified with sodium citrate, using an extra cycle of centrifugation a redispersion with a solution of $10 \mathrm{mM}$ citNa, followed by an overnight incubation. Alternatively, a solution of thiolPEG-carboxylic acid (thiol-PEG) $50 \mu \mathrm{g} / \mathrm{mL}$ was used to modify the surface of the AuNRs to provide stabilization. The absorption spectra of the particles dispersions were acquired using a Biotek Synergy 2, plate reader, while the size and aspect ratio of the nanorods in a batch were determined using Image J software ${ }^{35}$ on a collection of at least 10 TEM image, each containing from 50-300 particles. All the images were acquired using a Philips CM300 FEG TEM operating at $300 \mathrm{kV}$.

2.3. Preparation of Antimicrobial Film and Study of CVAuNRs Interaction. The preparation of the polyurethane/AuNRs/ crystal violet (PU/AuNRs/CV) film began by embedding the AuNRs into PU. The AuNRs were loaded on the PU film using the swellingencapsulation-shrink method. ${ }^{20}$ The PU film was exposed to a solution containing $90 \%$ of acetone and $10 \%$ of the AuNRs colloidal solution (optical density 1.5 , approximately $0.127 \mathrm{mg} / \mathrm{mL}$ ) to obtain an approximated concentration of $0.345 \mathrm{mM}$ of $\left[\mathrm{Au}_{0}\right]$ absorbed on 30 $\mathrm{cm}^{2}$ of PU film. After overnight incubation, the samples were washed with deionized water, and the remaining acetone was evaporated from the film until the polymer was shrunk to the original dimension. The $\mathrm{CV}$ dye was then absorbed on the AuNRs embedded PU film by diffusion incubating $1 \mathrm{~cm}^{2}$ tiles of the modified polymer in a solution of $1 \mathrm{mM}$ crystal violet for $48 \mathrm{~h}$ (approximated concentration in the polymer $0.325 \mathrm{mM}$ ). The resulting film is denoted as PU/AuNRs/CV 
film. The interaction in solution between $\mathrm{CV}$ dye and AuNRs stabilized with the two different methods was performed by measuring the UV-vis absorption of $10 \mu \mathrm{M}$ of CV containing $20 \% \mathrm{v} / \mathrm{v}$ of AuNRs $(\approx 30 \mu \mathrm{M})$, after $30 \mathrm{~s}$ of vortex agitation.

2.4. Antimicrobial Activity Test and ROS Production Quantification. The antimicrobial activity of the AuNRs embedded PU impregnated with CV (PU/AuNRs/CV) film was tested in a humid environment, where $1 \mathrm{~cm}^{2}$ of the film was inoculated with 25 $\mu \mathrm{L}$ of bacterial dispersion (E. coli ATC25922, $10^{8} \mathrm{cfu} / \mathrm{mL}$ ), to have a starting point of $2.5 \times 10^{6} \mathrm{cfu}$. The source of light used for the tests was a $28 \mathrm{~W}$ Wattmiser GE lamp, a high efficiency neon lamp commonly diffused in Europeans hospital and commercial buildings. The samples were tested in triplicate and covered with microscope coverslip to preserve the samples humidity during the time of light exposure. After the exposure period, the tiles of polymer and the coverslips were introduced in a $50 \mathrm{~mL}$ centrifuge tube and vortexed with $2 \mathrm{~mL}$ of $0.9 \% \mathrm{NaCl}$ solution to collect all the surviving bacteria. The solution obtained was aliquoted on nutrient agar plates and incubated for an overnight at $37{ }^{\circ} \mathrm{C}$ with controlled humidity in a Binder incubator (Red Line). During the incubation time, every living bacteria plated on nutrient agar formed visible colonies that were counted to calculate the efficiency of system. ${ }^{36}$ The film samples were tested for activity in different exposure times $(1,1.5,2$, and $3 \mathrm{~h})$ and per activity at different illumination intensities (8.7, 9.4, and 11.7 klux) at 2 and $3 \mathrm{~h}$ time points.

To confirm the mechanism of the antimicrobial effect, the production of ROS in the system was calculated using a modified version of the oxygen radical absorbance capability (ORAC) assay ${ }^{37,38}$ by measuring the variation of fluorescence intensity of a $0.5 \mu \mathrm{g} / \mathrm{mL}$ fluorescein solution, ${ }^{39}$ alkalinized with $50 \mu \mathrm{L}$ of $1 \mathrm{M} \mathrm{NaOH}$, when exposed for $1 \mathrm{~h}$ to 11.7 klux of white light using the same set up used for the antimicrobial experiments. The photobleaching rate of a fluorescein solution in alkaline condition was constant and reported in literature; ${ }^{40,41}$ thus, the difference of fluorescence between the solutions exposed to light on the surface of unmodified $\mathrm{PU}$ or on $\mathrm{PU} / \mathrm{CV}$ and PU/citNa-AuNRs/CV could be used to determine the amount of ROS produced using the Stern-Volmer ${ }^{39}$ equation and confirmed using a calibration with aliquots of $1,5,7.5,10$, and 12.5 $\mathrm{mM} \mathrm{H}_{2} \mathrm{O}_{2}$ on the fluorescein solution exposed to light for $1 \mathrm{~h}$ on PU.

All the fluorescence intensity measurements were performed with a Biotek plate reader with excitation filter $485 / 20$, emission filter 580 / 20, gain 70, and mirror position $635 \mathrm{~nm}$. The main emission peak of fluorescein was located at $515 \mathrm{~nm}$, and the fluorescence intensity was measured with a filter at $580 \pm 20 \mathrm{~nm}$ on the tail of the peak to avoid the interference of the excitation wavelength (calibration curve in the SI, Figure S1). The importance of the radical production for the efficiency of the system was confirmed adding $20 \mathrm{mM}$ of L-ascorbic acid at $\mathrm{pH} 7$ to the solution containing the bacteria $(0.9 \% \mathrm{NaCl}$ in water). In the experiment, L-ascorbic acid acted as an antioxidant to scavenge the ROS generated by the system ${ }^{42}$ and thus reduce the number of bacteria killed by the film.

\section{RESULTS AND DISCUSSION}

We have reasoned that the activity of the film derives from the interaction between the excited state of the crystal violet (CV) dye and the AuNRs both encapsulated in the PU film. AuNRs have a broad absorption spectrum and greater absorption coefficient compared to organic dyes ${ }^{43}$ and thus higher capability to concentrate the energy absorbed in a localized electrical field. ${ }^{29}$ If the AuNRs are dispersed in a fluid, the fastchanging electrical field releases the energy absorbed on the environment under the hyperthermal effect. ${ }^{44}$ While, when they are embedded in the polymer matrix, this route of energy relaxation is not available because the particles are confined. In this condition, the presence of dye molecules in close proximity to the particles induced a strong plasmonic coupling between dye and AuNRs, thanks to the overlapping of their absorption spectra due to the bespoke short rods, which greatly increased the amount of energy absorbed by the dye $\mathrm{e}^{45,46}$ and consequently increased the amount of ROS generated and the antimicrobial effect generated by the film (Figure 1). ${ }^{47}$

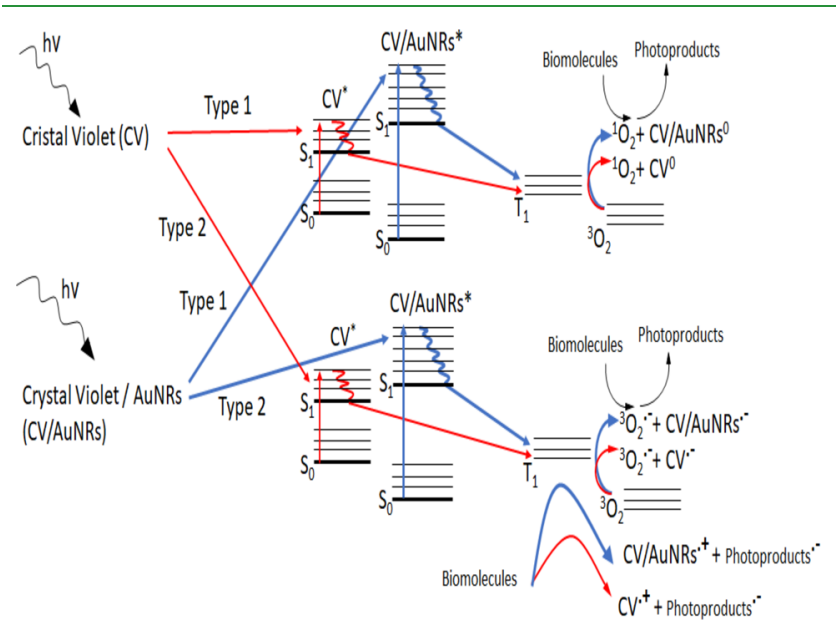

Figure 1. Overview of the photochemical mechanism of ROS generation for $\mathrm{CV}$ and $\mathrm{CV} / \mathrm{AuNR}$ films.

To understand if the antibacterial action of the film has a component of hyperthermia, the temperature changes of the polymer exposed to light have been tracked with a thermocouple. Results show no measurable variation between the unmodified PU and for the PU/citNa-AuNRs/CV film (temperature measurements for $2 \mathrm{~h}$ experiment in the SI, Figure S2). To complete our exploration of the system, we have conducted systematic characterization to the film and a comprehensive study of the interactions between $\mathrm{CV}$ dye and AuNRs with desired aspect ratio and surface coating before testing their antibacterial action. Details are given in the following sections.

3.1. Gold Nanorods Characterization. To match the CV's absorption for efficient energy transfer, AuNRs with an intense longitudinal LSPR peak at $650 \mathrm{~nm}$, Figure 1, have been synthesized. The particles after the synthesis were immersed in a concentrated solution of CTAB; this surfactant was necessary for the synthesis, but it was positively charged and toxic. The removal process, explained in the Materials and Methods section, managed a complete exchange of the CTAB surfactant with PSSNa, which was negatively charged. PSSNa weakly absorbs on the surface of the particles and could easily be replaced by nontoxic stabilizer, that is, sodium citrate (citNa, negatively charged) or thiol-PEG (weak negative charge). The exchange of CTAB with citNa or thiol-PEG blue-shifted the lateral surface plasmon resonance peak of the particles by 10 $\mathrm{nm}$ due to the change of the refractive index of the solution and the density of charges in surrounding medium of the particles, Figure 2. ${ }^{48}$

The dimensions of the particles were obtained analyzing TEM pictures: 20 to $30 \mathrm{~nm}$ length (L) and of 7 to $14 \mathrm{~nm}$ diameter (D), resulting in an average aspect ratio of $2.1 \pm 0.3$ $\mathrm{L} / \mathrm{D}$. The TEM images were taken after the elimination of $\mathrm{CTAB}$ because the surfactant forms crystals during the preparation of the samples, which interfere with the quality of the pictures. The TEM characterization of the size and aspect ratio of the gold nanorods has been performed on particles stabilized by citrate (Figure 3 ). Citrate stabilization gives to the AuNRs a shelf life 2 months if stored at $4{ }^{\circ} \mathrm{C}$. 


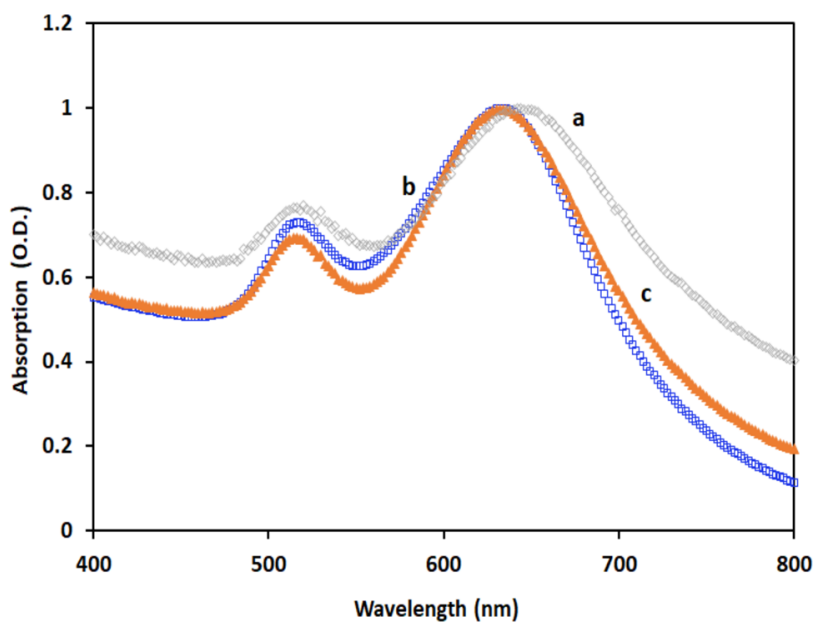

Figure 2. UV-visible spectra of AuNRs (a) in the presence of CTAB; (b) after $\mathrm{CTAB}$ removal and substitution with thiol-poly ethylene glycol-carboxylic acid; or (c) substitution with sodium citrate.
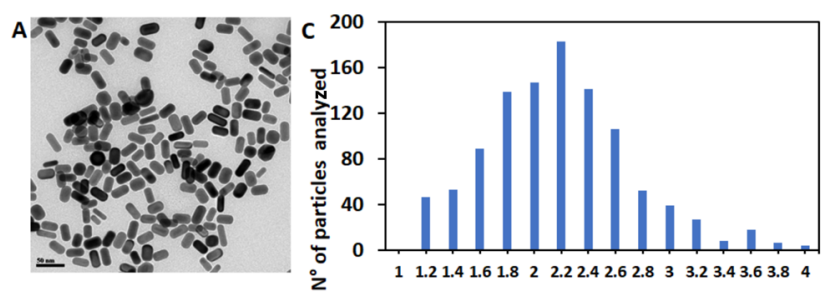

Aspect Ratio (L/D)
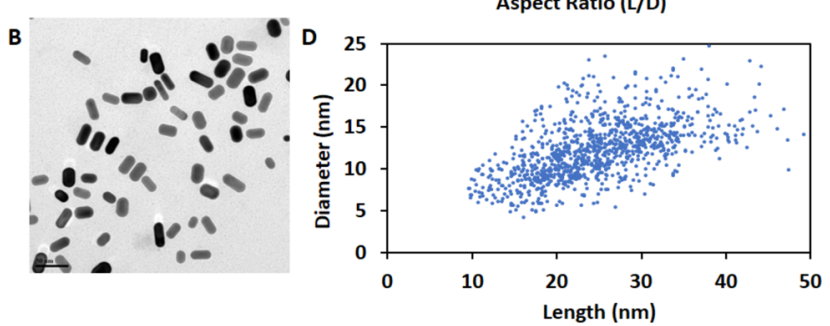

Figure 3. TEM analysis of the cit-AuNRs: (A) TEM picture at $25000 \times$ magnifications; (B) TEM picture at $39600 \times$ magnifications; (C) distribution of aspect ratios; and (D) size distribution.

3.2. Study of CV Interaction with AuNRs. To affirm our hypothesis that the antimicrobial action of the system relied on the interaction of $\mathrm{CV}$ dye with the AuNRs in the polymer matrix, their interactions (both with the thiol-PEG and citNa stabilized AuNRs) in solution have been studied by measuring the UV-vis spectrum of the mixture of AuNRs with CV, Figure 4.

Thiol-PEG is a very effective steric stabilizer due to its large molecular weight $(3500 \mathrm{Da})$; when used to stabilize gold nanoparticles, it formed a thick polymeric coating with a weak negative charge. ${ }^{49} \mathrm{CitNa}$ instead have a smaller molecular weight $(189.1 \mathrm{Da})$ and a strong negative charge ${ }^{50}$ forming a thin charged layer on the surface of the particles. This difference of stabilizer thickness and surface charge influenced the interactions between AuNRs and dye, as shown from the changes in the absorption spectra of the two mixed samples. The CV molecules (positively charged) had a signature peak at $590 \mathrm{~nm}$ and a shoulder peak at $580 \mathrm{~nm}$. When mixed with AuNRs, a significant peak at $520 \mathrm{~nm}$ was observed for the citNa-coated AuNRs, and similar, but less intense, for the thiolPEG coated one. These peaks can be seen in the spectra of the mixed solution and from subtraction of the spectra of $10 \mu \mathrm{M}$

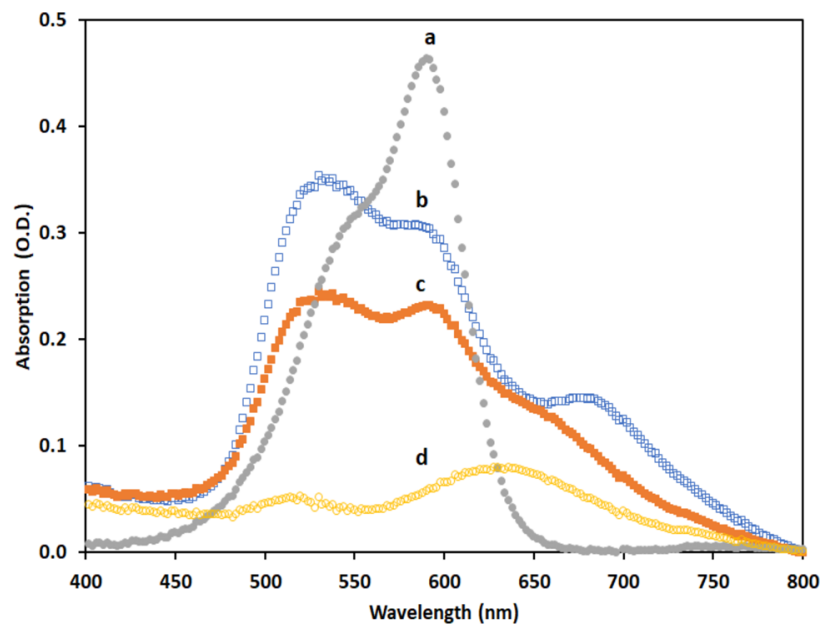

Figure 4. UV-visible spectra of (a) CV $10 \mu \mathrm{M}$, (b) citNa coated AuNRs in the presence of $10 \mu \mathrm{M} \mathrm{CV}$, (c) thiol-PEG-AuNRs in the presence of $10 \mu \mathrm{M} \mathrm{CV}$, (d) $20 \%(\approx 30 \mu \mathrm{M})$ citNa coated AuNRs.

$\mathrm{CV}$ and $30 \mu \mathrm{M}$ nanorods solutions in the SI, Figure S3. The AuNRs shown in Figure $4 d$ were stabilized with citNa; the particles stabilized in the two methods had similar spectra for very low concentrations (spectra reported in the Supporting Information Figure S3). Since the citNa coating was composed of a thin layer of small molecules (MW of citNa is $189.1 \mathrm{Da}$ ), the strong electrostatic interaction between $\mathrm{CV}$ and citNa allowed $\mathrm{CV}$ molecules to come close enough to the AuNRs surface, which improved the coupling effect between the SPR of the particles and the dye, which generated an efficient absorption enhancement of the peak at $520 \mathrm{~nm}^{45,46,51}$ It is worth noticing that both spectra of mixed solutions containing AuNRs either coated with citNa or thiol-PEG show a strong reduction of the $\mathrm{CV}$ peak at $590 \mathrm{~nm}$ wavelength, suggesting the presence of a strong plasmonic and electronic interaction between the dye and the nanorods. In addition to the confirmation of CV-AuNRs interactions, especially in the citNa-AuNRs, the comparison of the spectra between 660 and $700 \mathrm{~nm}$ shows that in solution AuNRs aggregate in the presence of $\mathrm{CV}$ molecules. The degree of aggregation (broadening of the peak at that wavelength range) was more evident for citNa coated AuNRs than thiol-PEG coated AuNRs. This could be an additional evidence of $\mathrm{CV}$-nanorods interaction because $\mathrm{CV}$ neutralize the surface charge and thus removal of electrostatic protection in citNa-coated AuNRs. This aggregation in solution is however a not a concern for the efficiency of the antibacterial system because the nanoparticles and the dye were added to the polymeric matrix with two different processes, trapping the nanorods inside the PU film with swelling/shrinking method and later diffusing the dye into the polymer.

3.3. PU/AuNRs/CV Film Characterization. The embedment of AuNRs in the polyurethane polymer was confirmed by comparing the UV-visible spectra of the polymer before (Figure $5 \mathrm{~A}(\mathrm{a})$ ) and after embedding the AuNRs (Figure $5 \mathrm{~A}(\mathrm{~b}))$. By subtracting the two spectra, it was possible to see that the characteristic peaks of the AuNRs at 520 and $640 \mathrm{~nm}$ (Figure 5A(c)) were maintained, signaling that AuNRs were not aggregated.

As showed in Figure 5B, CV maintain the characteristic two peaks structure after the diffusion in the polymer (Figure $5 \mathrm{~B}(\mathrm{~d}))$. When the polymer contained both AuNRs and dye, 

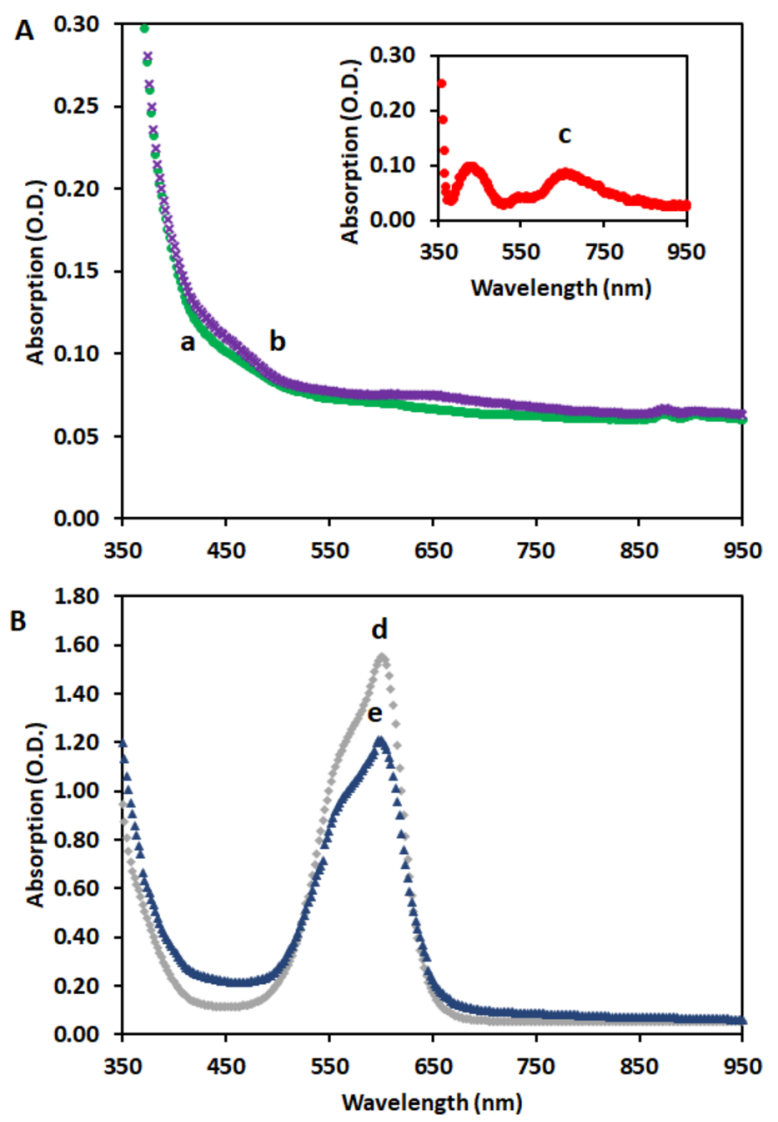

Figure 5. (A) UV-visible spectra of (a) PU, (b) PU/citNa-AuNRs film. (c) Subtraction curve (b-a); (B) UV-visible spectra of (d) PU/ $\mathrm{CV}$ and (e) PU/citNa-AuNRs/CV. All data have been normalized to compensate the diffraction of the polymeric film.

the peak intensity of the dye absorption decreased (Figure $5 \mathrm{~B}(\mathrm{e})$ ) as previously seen for the samples in solution (Figure 4b). AuNRs alone in the polymer showed an increase of the absorption at shorter wavelength; this effect is also shown in the full complex (Figure $5 \mathrm{~B}(\mathrm{e})$ ). This variation of the absorption shows how the optical properties of the dyes and the AuNRs were influenced by their interactions within the confined space of the polymeric matrix. This could be that different energy absorptions became more accessible. The intensity of the AuNRs peaks detected in the polymer increased linearly with the increase of concentration used in the swelling/encapsulation/shrink process, which confirmed the reproducibility of the embedding process (Figure S4).

For the preparation of the samples used in this work, an AuNRs dispersion of 1.5 O.D. had been used (final concentration in the polymer $0.345 \mathrm{mM}$ ) because higher concentrations caused saturation and did not improve the performance of the film. The subsequent step in the film preparation was the diffusion of $\mathrm{CV}$ in the polymer; to determine the optimal time needed for the process, the amount of CV diffused in the PU/AuNRs film over a range of 0-90 h of incubation time was measured using UV-visible absorption spectra. It was found that, for the fixed CV concentration of 1 $\mathrm{mM}$, near solubility concentration, the amount of dye diffused in the polymer increased linearly for the first $8 \mathrm{~h}$ and settled to a slow increase until $30 \mathrm{~h}$, where the progression reached a plateau (Figure S5, Supporting Information). The ideal diffusion time for the samples used in the article was set to
$48 \mathrm{~h}$, equivalent to an approximated concentration in the polymer of $0.325 \mathrm{mM}$; for a ratio dye/nanorods of approximately $1: 1$, the penetration of the dye in the polymeric matrix was visible to naked eyes and uniform for all the thickness of the film.

3.4. Quantification of ROS Production. Control tests with identical set up to the antimicrobial testing, Figure 6, were

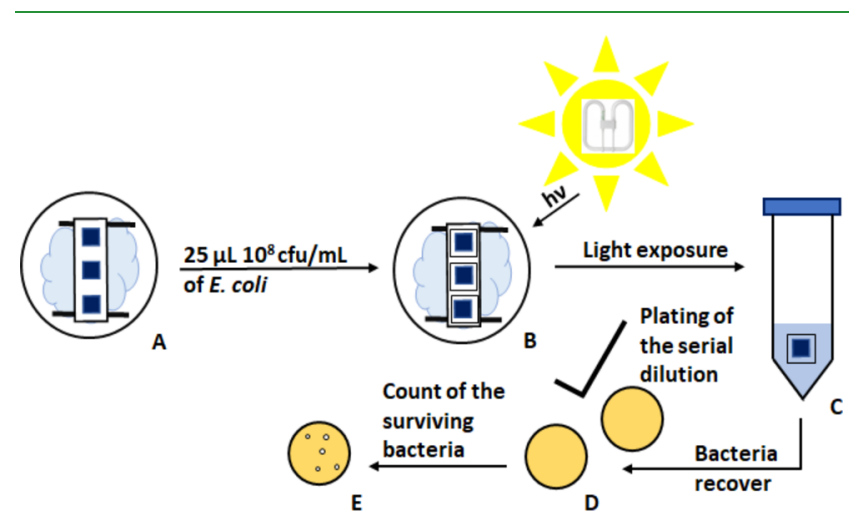

Figure 6. Scheme of the antibacterial film testing procedure: (A) PU/ AuNRs/CV film samples are supported on a slide over some bidistilled water to prevent dehydration; (B) after the inoculation with bacteria cells, the samples are protected with glass coverslips; (C) film samples and coverslips are washed with $\mathrm{NaCl} 0.9 \%$ to recover the remaining bacteria if any; (D) bacteria solution is serially diluted and plated on nutrient agar and (E) the colony formed are counted.

performed on a solution of fluorescein $0.5 \mu \mathrm{g} / \mathrm{mL}$ alkalinized with $\mathrm{NaOH} 5 \mathrm{mM}$ to confirm the hypothesis that the antimicrobial action was attributable to the generation of $\operatorname{ROS}^{52}$ and to quantify the effect of the nanorods on their production.

Fluorescein in alkaline environment produced a strong fluorescence emission at $520 \mathrm{~nm}$ (absorption $480 \mathrm{~nm}$ ), which was progressively quenched when exposed to light and more rapidly reduced after the interaction with oxygen reactive species. ${ }^{37}$ The magnitude of the reduction of fluorescence intensity, for a quenching process driven by the interaction between fluorescein and a quencher in solution, was modeled by the Stern-Volmer equation for a bimolecular quenching driven by diffusion: ${ }^{39}$

$$
\frac{I_{0}}{I}=1+\tau_{0} k_{q}[Q]
$$

Where $I_{0}$ was the fluorescence of a fluorescein solution exposed to light for $1 \mathrm{~h}$ on the surface of unmodified polymer, $I$ was the fluorescence intensity of the solution exposed to light for $1 \mathrm{~h}$ on the surface of a polymer modified with $\mathrm{CV}$ or $\mathrm{CV}$ and citNa-AuNRs, $\tau_{0}$ was the fluorescence decay in absence of a quencher at $25^{\circ} \mathrm{C}(3.60 \mathrm{~ns}), k_{\mathrm{q}}$ was the bimolecular quenching rate constant at $25{ }^{\circ} \mathrm{C}\left(7.64 \times 10^{9} \mathrm{M}^{-1} \mathrm{~s}^{-1}\right)$, and [Q] was the concentration of the quencher. The calculation shows a ROS production of $3.03 \pm 0.60 \mathrm{mM}$ per hour for the $\mathrm{PU} / \mathrm{CV}$ film and $5.26 \pm 0.02 \mathrm{mM}$ for the PU/citNa-AuNRs/CV film. To confirm the ROS production, experimental results were obtained from a calibration curve measuring the fluorescence of the fluorescein solution after exposure to light for $1 \mathrm{~h}$ on unmodified polymer and simulating the production of ROS with aliquots of $\mathrm{H}_{2} \mathrm{O}_{2}$ and incubating in the dark overnight (Figure S1, Supporting Information). The ROS concentration measured with the calibration curve showed comparable results 
with the theory, but it introduced some variability due the increased amount of experimental procedure required to obtain the results $(2.24 \pm 1.94 \mathrm{mM}$ for polymer and $\mathrm{CV}$, $5.32 \pm 2.65 \mathrm{mM}$ for the sample containing CV and AuNRs). The agreement between the results obtained theoretically and from the calibration with hydrogen peroxide suggested that the main radical species generated by the film is the hydroxyl radical, which is the most favorite product of the decomposition of $\mathrm{H}_{2} \mathrm{O}_{2}$ in the condition of the experiment. ${ }^{53}$ The importance of the production of ROS for the action of the system has been further confirmed by adding L-ascorbic acid $20 \mathrm{mM}$ buffered at $\mathrm{pH} 7$ to the bacteria dispersion, which, being an antioxidant, had the ability to quench the amount of ROS released by the film. With the introduction of $20 \mathrm{mM} \mathrm{L}$ ascorbic acid to the system, the activity of the film was indeed reduced by approximately 15 -times.

3.5. Antibacterial Tests. As discussed earlier, citNa stabilized AuNRs can interact with CV effectively through electrostatic interaction. Thus, the polymeric film embedded with citNa AuNRs (PU/citNA-AuNRs/CV) was tested against E. coli (starting concentration $2.5 \times 10^{8}$ ) for $1 \mathrm{~h}, 1.5 \mathrm{~h}, 2 \mathrm{~h}$, and $3 \mathrm{~h}$ of 11.7 klux of light exposure and for 2 and $3 \mathrm{~h}$ of exposure to different light intensities. To confirm the activity of the antimicrobial film, controls of PU alone, PU modified with AuNRs, and modified with $\mathrm{CV}$ alone were tested for the antibacterial action under same amount of light exposure and time. Results showed that in the first hour of the exposure, the bacteria on the $\mathrm{PU} / \mathrm{citNa}-\mathrm{AuNR} / \mathrm{CV}$ polymer sample were reduced of an order of magnitude (1-log reduction). By extending the time exposure to $1.5,2$, and $3 \mathrm{~h}$, the population of bacteria decreased exponentially to 2-log, 3-log, and 3.5-4$\log$, respectively ( $3 \mathrm{~h}$ was the longest time tested) (Figure $7 \mathrm{~d}, \mathrm{e})$.

This rate of antibacterial activity, 4-log in $3 \mathrm{~h}$, is particularly interesting against gram $(-)$ bacteria, which possess a double layer bacterial membrane and they are generally resistant to this kind of sterilization. ${ }^{20}$ Our results were a significant improvement compared to the results reported in literature for

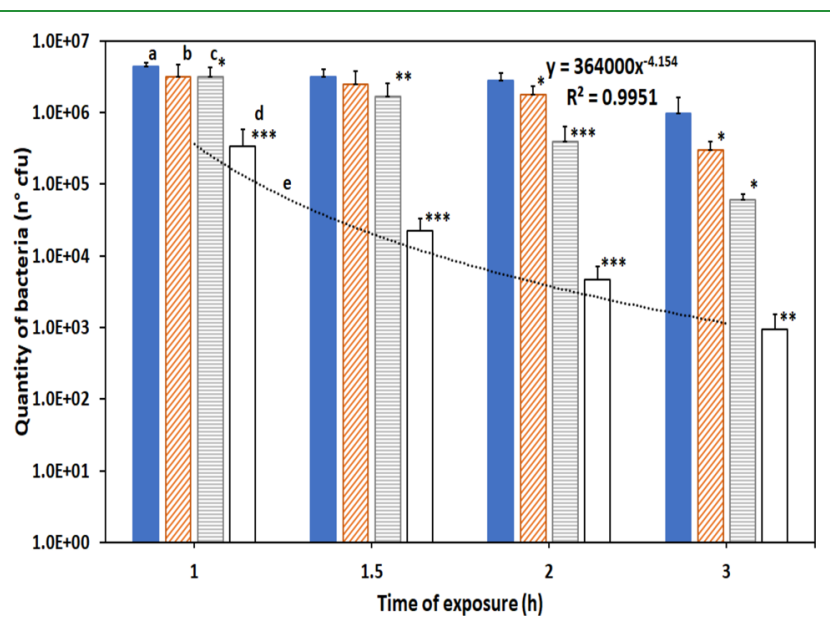

Figure 7. Antibacterial effect against E. coli of $2.5 \times 10^{6}$ at starting count. Remaining bacteria count with (a) PU polymer alone, (b) polymer with citNa-AuNRs, (c) polymer with $\mathrm{CV}$, and (d) full complex PU/citNa-AuNRs/CV film measured at different light exposure time of $1,1.5,2$, and $3 \mathrm{~h}$. (e) Fitting for the rate of bacteria elimination for the PU/citNa-AuNRs/CV film. $* p<0.05$, $* *$ $p<0.01, * * * p<0.001$. spherical $\mathrm{Au}$ nanoparticles, which needed much longer of light exposure $(6 \mathrm{~h})$. The control films, which were tested separately, retained only a limited efficiency, with activity reduced of orders of magnitude compared with the full complex. For example, the controls containing only polymer and citNa-AuNRs (without CV) had barely any effect on the bacteria population until the $3 \mathrm{~h}$ time point (reduced by 1-log only), while the PU/CV sample maintained a fraction of the activity, reducing the bacteria population of less of an order of magnitude after $2 \mathrm{~h}$ and $1.25-1.5-\log$ after $3 \mathrm{~h}$. The importance of the AuNRs-CV interaction (or CV binding to AuNRs) for an effective antibacterial action was affirmed by the experiment using thiol-PEG modified AuNRs. The PU/ thiol-PEG-AuNRs/CV film had only a small antibacterial activity (no reduction of bacterial count after $2 \mathrm{~h}$ exposure, and merely $0.5-\log$ reduction after $3 \mathrm{~h}$ light exposure, $p<0.0001$ ). As discussed earlier, gold nanorods with thiol-PEG coating had a weak negative charge, which hindered the interaction with the positively charged $\mathrm{CV}$ dye, as shown from the interaction in solution in Figure 4. To understand the relation between the intensity of the light and the speed of the bacterial reduction, the antimicrobial film (PU/citNA-AuNRs/CV) was subsequently tested for 2 and $3 \mathrm{~h}$ action with reduced intensity of illumination from 11.7 klux to 9.4 klux and 8.7 klux. The system was also tested in the absence of light to check the chemical toxicity of the modified polymeric film (Figure 8B(a)).

Results showed that the same film samples kept in the dark did not possess any intrinsic toxicity, (Figure $8 \mathrm{~B}(\mathrm{a})$ ), which confirmed that light-film interaction was pivotal for bacteria reduction. Furthermore, the degree of bacteria reduction was dependent on the level of illumination; reducing the light given to the film to produce ROS slowed down their production and consequently the bacteria killings. Specifically, the efficiency of the system increased exponentially with the increase of light intensity and the time of the exposure (Figure $8 \mathrm{~B}(\mathrm{~b}-\mathrm{d})$ ). The light intensity dependency of the film action was consistent for both the 2 and $3 \mathrm{~h}$ exposure time points (Figure 8A). This means that given a certain amount of time it would be possible to estimate the bacterial reduction according to the intensity of the light and the time needed to reach a complete kill of the bacteria. In a normal working condition, the film will not be constantly exposed to 8 to 11.7 klux of light intensity but would be exposed to a more usual lighting intensity of approximately 1 klux, in which the production of ROS for the film was not detectable. Higher light intensity would only be applied during a routine sterilization process or during operations that need constant sterility as a surgical procedure. Limiting the activated period of the film to short period greatly reduced the risk for the bacteria to develop bacteria resistance. In literature, similar antimicrobial films could resist to a month of continuous light exposure; ${ }^{20}$ limiting the exposure of the film to high intensity light will extend the life of the film to months of use.

With the optimal design of the polymer film, embedded with anisotropic AuNRs of appropriate aspect ratio and a proper surface coating which facilitates interaction with the CV dye, our film provides efficient antibacterial action under white light. It did not depend on specialized sources of light, for example, UV lamps and lasers, and showed no toxic effects when not activated. 

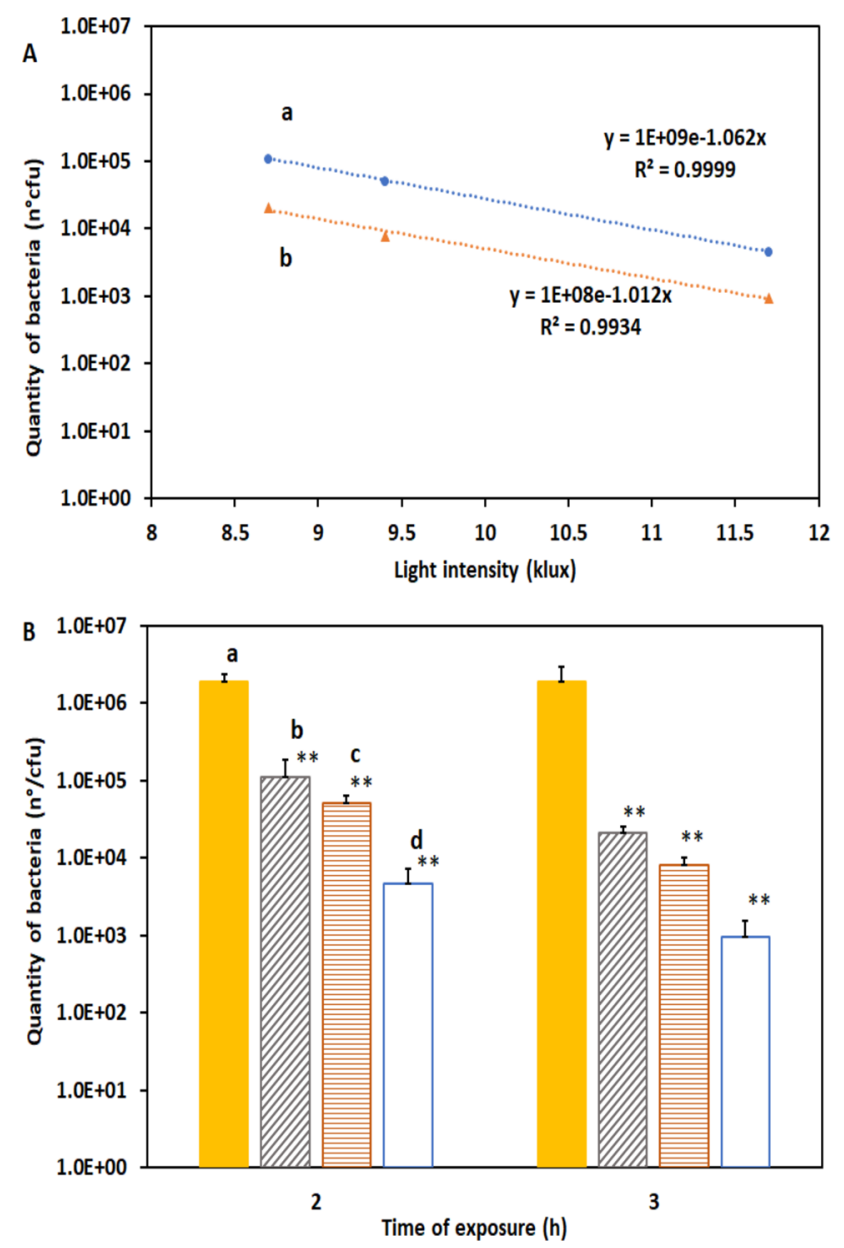

Figure 8. Effect of light power on the action; (A) bacteria count after (a) $2 \mathrm{~h}$ and (b) $3 \mathrm{~h}$ light exposition in relation of the light intensity. (B) Bacteria count for different light intensity after 2 and $3 \mathrm{~h}$ : (a) samples kept in the dark; (b) light exposure of $8.7 \mathrm{klux}$; (c) light exposure of 9.4 klux; and (d) light exposure of 11.7 klux; $* * p<0.01$.

\section{CONCLUSION}

We reported a novel nanoplasmonic based antibacterial polymer film. It consisted of anisotropic AuNRs and an organic dye capable of generating ROS. The principle of action of this film was based on the plasmonic coupling interaction of AuNRs and the nearby dye both confined in a polymer film under normal lighting, which allow for effective generation of ROS in quantifiable amounts. This antibacterial film offered a vital alternative for continuous background bacterial reduction without requiring the active use of chemicals or the use of energetic radiations and thus allowing the continuation of the operation in the sterile environment during the sterilization. The film was able to reduce the number of Gram-negative bacteria on its surface from a concentration of $10^{4} \mathrm{cfu} / \mathrm{cm}^{2}$ to the level of $1-5 \mathrm{cfu} / \mathrm{cm}^{2}$, acceptable for a hospital surface after $3 \mathrm{~h}$ of light exposure. For the first time, it was demonstrated that the produced film could kill Gram-negative bacteria, which are more difficult to eradicate. The low toxicity when not exposed to light and the practicality of having an antimicrobial device embedded on a solid-state polymeric film makes it a promising candidate for future applications and a practical solution for the problem of maintaining sterility in environments in contact with the public and to further reduce the pandemic diffusion of antimicrobial drug resistance.

\section{ASSOCIATED CONTENT}

\section{Supporting Information}

The Supporting Information is available free of charge on the ACS Publications website at DOI: 10.1021/acsabm.9b00343.

Calibration curve of ROS generated by the system; time/temperature analysis; detailed subtraction of spectra of particles and dye from spectra of the mix; absorption at $648 \mathrm{~nm}$ of polymeric samples; tracking of absorption at $600 \mathrm{~nm}$ of polymeric samples (PDF)

\section{AUTHOR INFORMATION}

\section{Corresponding Authors}

*E-mail: ntk.thanh@ucl.ac.uk.

*E-mail: xd-su@imre.a-star.edu.sg.

ORCID

Nguyêิn T. K. Thanh: 0000-0002-4131-5952

Notes

The authors declare no competing financial interest.

\section{ACKNOWLEDGMENTS}

N.T.K.T. thanks EPSRC (EP/M018016/1 and EP/M015157/ 1) and AOARD (FA2386-17-1-4042 award) for funding, and F.R. thanks UCL and the ARAP program of A*STAR for the scholarship and facilities.

\section{REFERENCES}

(1) Biggest Threats and Data. Antibiotic/Antimicrobial Resistance; CDC: Atlanta, GA, 2013.

(2) O’Neill, J. Antimicrobial Resistance: Tackling a Crisis for the Health and Wealth of Nations. Review on Antimicrobial Resistance; HM Government: London, 2014.

(3) Allegranzi, B.; Nejad, S. B.; Combescure, C.; Graafmans, W.; Attar, H.; Donaldson, L.; Pittet, D. Burden of Endemic Health-CareAssociated Infection in Developing Countries: Systematic Review and Meta-Analysis. Lancet 2011, 377 (9761), 228-241.

(4) Scallan, E.; Hoekstra, R. M.; Angulo, F. J.; Tauxe, R. V.; Widdowson, M.-A.; Roy, S. L.; Jones, J. L.; Griffin, P. M. Foodborne Illness Acquired in the United States-Major Pathogens. Emerging Infect. Dis. 2011, 17 (1), 7-15.

(5) Stone, P. W.; Pogorzelska, M.; Kunches, L.; Hirschhorn, L. R. Hospital Staffing and Health Care-Associated Infections: A Systematic Review of the Literature. Clin. Infect. Dis. 2008, 47 (7), 937-944.

(6) Current Good Manufacturing Practices (CGMPs) - Food CGMP Modernization Report; Center for Food Safety and Applied Nutrition, 2005.

(7) Dancer, S. J. Controlling Hospital-Acquired Infection: Focus on the Role of the Environment and New Technologies for Decontamination. Clin. Microbiol. Rev. 2014, 27 (4), 665-690.

(8) Page, K.; Wilson, M.; Parkin, I. P. Antimicrobial Surfaces and Their Potential in Reducing the Role of the Inanimate Environment in the Incidence of Hospital-Acquired Infections. J. Mater. Chem. 2009, 19 (23), 3819.

(9) Hultman, J.; Rahkila, R.; Ali, J.; Rousu, J.; Björkroth, K. J. Meat Processing Plant Microbiome and Contamination Patterns of ColdTolerant Bacteria Causing Food Safety and Spoilage Risks in the Manufacture of Vacuum-Packaged Cooked Sausages. Appl. Environ. Microbiol. 2015, 81 (20), 7088-7097.

(10) European Union. COMMISSION REGULATION (EC) No 2073_2005 on Microbiological Foodstuffs. Off. J. Eur. Union 2005, I, $338-363$.

(11) Amodio, E.; Dino, C. Use of ATP Bioluminescence for Assessing the Cleanliness of Hospital Surfaces: A Review of the Published Literature (1990-2012). J. Infect. Public Health 2014, 7 (2), 92-98. 
(12) Carling, P. C.; Bartley, J. M. Evaluating Hygienic Cleaning in Health Care Settings: What You Do Not Know Can Harm Your Patients. Am. J. Infect. Control 2010, 38 (5 Suppl 1), S41-50.

(13) Han, J.; Sullivan, N.; Leas, B. F.; Pegues, D. A.; Kaczmarek, J. L.; Umscheid, C. A. Cleaning Hospital Room Surfaces to Prevent Health Care-Associated Infections. Ann. Intern. Med. 2015, 163 (8), 598-607.

(14) Singh, B.; Sharma, N. Mechanistic Implications of Plastic Degradation. Polym. Degrad. Stab. 2008, 93 (3), 561-584.

(15) Irving, D.; Lamprou, D. A.; Maclean, M.; MacGregor, S. J.; Anderson, J. G.; Grant, M. H. A Comparison Study of the Degradative Effects and Safety Implications of UVC and $405 \mathrm{Nm}$ Germicidal Light Sources for Endoscope Storage. Polym. Degrad. Stab. 2016, 133, 249254.

(16) Dancer, S. J. Controlling Hospital-Acquired Infection: Focus on the Role of the Environment and New Technologies for Decontamination. Clin. Microbiol. Rev. 2014, 27 (4), 665-690.

(17) Kangwansupamonkon, W.; Lauruengtana, V.; Surassmo, S.; Ruktanonchai, U. Antibacterial Effect of Apatite-Coated Titanium Dioxide for Textiles Applications. Nanomedicine 2009, 5 (2), 240249.

(18) Perni, S.; Piccirillo, C.; Pratten, J.; Prokopovich, P.; Chrzanowski, W.; Parkin, I. P.; Wilson, M. The Antimicrobial Properties of Light-Activated Polymers Containing Methylene Blue and Gold Nanoparticles. Biomaterials 2009, 30 (1), 89-93.

(19) Sehmi, S. K.; Noimark, S.; Bear, J. C.; Peveler, W. J.; Bovis, M.; Allan, E.; MacRobert, A. J.; Parkin, I. P. Lethal Photosensitisation of Staphylococcus Aureus and Escherichia Coli Using Crystal Violet and Zinc Oxide-Encapsulated Polyurethane. J. Mater. Chem. B 2015, 3 (31), 6490-6500.

(20) MacDonald, T. J.; Wu, K.; Sehmi, S. K.; Noimark, S.; Peveler, W. J.; Du Toit, H.; Voelcker, N. H.; Allan, E.; MacRobert, A. J.; Gavriilidis, A.; et al. Thiol-Capped Gold Nanoparticles SwellEncapsulated into Polyurethane as Powerful Antibacterial Surfaces under Dark and Light Conditions. Sci. Rep. 2016, 6, 1-11.

(21) Chen, H.; Shao, L.; Li, Q.; Wang, J. Gold Nanorods and Their Plasmonic Properties. Chem. Soc. Rev. 2013, 42 (7), 2679-2724.

(22) Imlay, J. A. The Molecular Mechanisms and Physiological Consequences of Oxidative Stress: Lessons from a Model Bacterium. Nat. Rev. Microbiol. 2013, 11 (7), 443-454.

(23) Otto, C.; Zahn, S.; Rost, F.; Zahn, P.; Jaros, D.; Rohm, H. Physical Methods for Cleaning and Disinfection of Surfaces. Food Eng. Rev. 2011, 3 (3-4), 171-188.

(24) Doan, L.; Forrest, H.; Fakis, A.; Craig, J.; Claxton, L.; Khare, M. Clinical and Cost Effectiveness of Eight Disinfection Methods for Terminal Disinfection of Hospital Isolation Rooms Contaminated with Clostridium Difficile 027. J. Hosp. Infect. 2012, 82 (2), 114-121.

(25) Abreu, A. C.; Tavares, R. R.; Borges, A.; Mergulhao, F.; Simoes, M. Current and Emergent Strategies for Disinfection of Hospital Environments. J. Antimicrob. Chemother. 2013, 68 (12), 2718-2732.

(26) Rutala, W. A.; Weber, D. J. Guideline for Disinfection and Sterilization in Healthcare Facilities; CDC, 2008.

(27) Rutala, W. A.; Weber, D. J. Infection Control: The Role of Disinfection and Sterilization. J. Hosp. Infect. 1999, 43 (Suppl), S4355.

(28) Nikoobakht, B.; El-Sayed, M. A. Preparation and Growth Mechanism of Gold Nanorods (NRs) Using Seed - Mediated Growth Method. Chem. Mater. 2003, 15 (16), 1957-1962.

(29) Pallares, R. M.; Su, X.; Lim, S. H.; Thanh, N. T. K. Fine-Tuning of Gold Nanorod Dimensions and Plasmonic Properties Using the Hofmeister Effects. J. Mater. Chem. C 2016, 4 (1), 53-61.

(30) Becker, J.; Trügler, A.; Jakab, A.; Hohenester, U.; Sönnichsen, C. The Optimal Aspect Ratio of Gold Nanorods for Plasmonic BioSensing. Plasmonics 2010, 5 (2), 161-167.

(31) Mehtala, J. G.; Zemlyanov, D. Y.; Max, J. P.; Kadasala, N.; Zhao, S.; Wei, A. Citrate-Stabilized Gold Nanorods. Langmuir 2014, 30 (46), 13727-13730.

(32) Sahu, P.; Prasad, B. L. V. Time and Temperature Effects on the Digestive Ripening of Gold Nanoparticles: Is There a Crossover from
Digestive Ripening to Ostwald Ripening? Langmuir 2014, 30 (34) 10143-10150.

(33) Alkilany, A. M.; Murphy, C. J. Toxicity and Cellular Uptake of Gold Nanoparticles: What We Have Learned so Far? J. Nanopart. Res. 2010, 12 (7), 2313-2333.

(34) Leonov, A. P.; Zheng, J.; Clogston, J. D.; Stern, S. T.; Patri, A. K.; Wei, A. Detoxification of Gold Nanorods by Treatment with Polystyrenesulfonate. ACS Nano 2008, 2 (12), 2481-2488.

(35) ImageJ; NIH, 2019. https://imagej.nih.gov/ij/? (accessed Jan 7, 2019).

(36) Turano, A.; Pirali, F. Quantification Methods in Microbiology. In Laboratory Diagnosis of Infectious Diseases; Springer New York: New York, 1988; pp 8-13.

(37) Ou, B.; Hampsch-Woodill, M.; Flanagan, J.; Deemer, E. K.; Prior, R. L.; Huang, D. Novel Fluorometric Assay for Hydroxyl Radical Prevention Capacity Using Fluorescein as the Probe. J. Agric. Food Chem. 2002, 50 (10), 2772-2777.

(38) Davalos, A.; Gomez-Cordoves, C.; Bartolomé, B. Extending Applicability of the Oxygen Radical Absorbance Capacity (ORACFluorescein) Assay. J. Agric. Food Chem. 2004, 52 (1), 48-54.

(39) Arik, M.; çelebi, N.; Onganer, Y. Fluorescence Quenching of Fluorescein with Molecular Oxygen in Solution. J. Photochem. Photobiol., A 2005, 170 (2), 105-111.

(40) Song, L.; Hennink, E. J.; Young, I. T.; Tanke, H. J. Photobleaching Kinetics of Fluorescein in Quantitative Fluorescence Microscopy. Biophys. J. 1995, 68 (6), 2588-2600.

(41) Martin, M. M.; Lindqvist, L. The PH Dependence of Fluorescein Fluorescence. J. Lumin. 1975, 10 (6), 381-390.

(42) Guaiquil, V. H.; Vera, J. C.; Golde, D. W. Mechanism of Vitamin C Inhibition of Cell Death Induced by Oxidative Stress in Glutathione-Depleted HL-60 Cells. J. Biol. Chem. 2001, 276 (44), 40955-40961.

(43) Jain, P. K.; Lee, K. S.; El-Sayed, I. H.; El-Sayed, M. A. Calculated Absorption and Scattering Properties of Gold Nanoparticles of Different Size, Shape, and Composition: Applications in Biological Imaging and Biomedicine. J. Phys. Chem. B 2006, 110, $7238-7248$.

(44) Bucharskaya, A. B.; Maslyakova, G. N.; Dikht, N. I.; Navolokin, N. A.; Terentyuk, G. S.; Bashkatov, A. N.; Genina, E. A.; Khlebtsov, B. N.; Khlebtsov, N. G.; Tuchin, V. V. Plasmonic Photothermal Therapy of Transplanted Tumors in Rats at Multiple Intravenous Injection of Gold Nanorods. Bionanoscience 2017, 7 (1), 216-221.

(45) Darby, B. L.; Auguié, B.; Meyer, M.; Pantoja, A. E.; Le Ru, E. C. Modified Optical Absorption of Molecules on Metallic Nanoparticles at Sub-Monolayer Coverage. Nat. Photonics 2016, 10 (1), 40-45.

(46) Ni, W.; Yang, Z.; Chen, H.; Li, L.; Wang, J. Coupling between Molecular and Plasmonic Resonances in Freestanding Dye-Gold Nanorod Hybrid Nanostructures. J. Am. Chem. Soc. 2008, 130 (21), 6692-6693.

(47) Khaing Oo, M. K.; Yang, Y.; Hu, Y.; Gomez, M.; Du, H.; Wang, H. Gold Nanoparticle-Enhanced and Size-Dependent Generation of Reactive Oxygen Species from Protoporphyrin IX. ACS Nano 2012, 6 (3), 1939-1947.

(48) Zijlstra, P.; Paulo, P. M. R.; Orrit, M. Optical Detection of Single Non-Absorbing Molecules Using the Surface Plasmon Resonance of a Gold Nanorod. Nat. Nanotechnol. 2012, 7 (6), 379-382.

(49) Zhang, Z.; Lin, M. Fast Loading of PEG-SH on CTABProtected Gold Nanorods. RSC Adv. 2014, 4 (34), 17760.

(50) Mehtala, J. G.; Zemlyanov, D. Y.; Max, J. P.; Kadasala, N.; Zhao, S.; Wei, A. Citrate-Stabilized Gold Nanorods. Langmuir 2014, 30, 13727-13730.

(51) Chen, H.; Ming, T.; Zhao, L.; Wang, F.; Sun, L.-D.; Wang, J.; Yan, C.-H. Plasmon-Molecule Interactions. Nano Today 2010, 5 (5), 494-505.

(52) Goswami, M.; Mangoli, S. H.; Jawali, N. Involvement of Reactive Oxygen Species in the Action of Ciprofloxacin against Escherichia Coli. Antimicrob. Agents Chemother. 2006, 50 (3), 949954. 
(53) Joshi, A. A.; Locke, B. R.; Arce, P.; Finney, W. C. Formation of Hydroxyl Radicals, Hydrogen Peroxide and Aqueous Electrons by Pulsed Streamer Corona Discharge in Aqueous Solution. J. Hazard. Mater. 1995, 41 (1), 3-30. 